\title{
Proposed new legislation for the care of mentally ill people in the community
}

\author{
Opinions of psychiatrists and social workers
}

\author{
S. Hampson and P. Davison
}

The Department of Health has publlshed proposals for new logistation, which it hopes will provide a logal basis for effective community care of mentally ili people. Consultant poychiatrists and approved social workers were surveyed to determine attitudes towards the proposals. Desplte the impression that new powers are provided, respondents saw little in the way of new powers, and could not see how the proposals would improve community care. Not all of the proposals were fully understood, and wider consultation with those who would be using any new legistation is recommended.

Under the 1983 Mental Health Act for England and Wales, there are two approaches to the community care of seriously mentally ill patients who lack insight into their need for treatment. The first approach is a guardianship order under which a guardian (usually a social worker) is given wide ranging powers similar to those of a parent over a child. Guardianship is rarely used however. The reasons for this are not known but it has been suggested that many social workers consider it unenforceable (Bluglass, 1993a).

The second approach to the community care of this group of patients is leave of absence. Under the 1983 Mental Health Act patients detained in hospital can be granted leave of absence by their consultant. If the patient's mental health deteriorates while on leave of absence he or she can be recalled to hospital. If a patient had not been recalled during the six months of the detention order he or she would cease to be liable to recall and detention.

In recent years there have been a series of proposals from interested bodies, in an attempt to establish some form of compulsory treatment in the community. In 1993 the Royal College of Psychiatrists proposed community supervision orders (Royal College of Psychiatrists, 1993). These proposals were rejected by the House of Commons Health Committee for a number of reasons, including the belief that they may contravene European law (Health Committee 5th Report, 1993).

Recently, the Secretary of State for Health has committed herself to finding an urgent solution to the problem this small group of seriously mentally ill patients poses. The sense of urgency was heightened when a patient with poorly controlled schizophrenia climbed into the lions' enclosure at London Zoo, attracting much publicity. Her solution was a number of proposals published in 1993 that came to be known as the Ten Point Plan (Department of Health, 1993; Bluglass, 1993b; Burns, 1994). They contain common sense re-statements of good clinical practice and also three new orders are proposed: supervised discharge; extended leave of absence, and extending current powers of guardianship.

Supervised discharge. Existing rules for patients detained under a section of the Mental Health Act 1983 would be used. To these would be added a negotiated discharge agreement which would provide a legal basis for community care. It is intended for patients who would pose a serious risk to their own health or safety or the safety of other people, unless care was supervised. The order requires a named key worker, a clear treatment plan negotiated with the patient, a requirement for the patient to reside at a specified place and to afford access to staff involved in the patient's care. The patient could be required to attend for treatment; in addition staff would have the power to convey patients to a place where treatment would be given. Having attended, it is unclear whether treatment can be given against his or her will. Responsibility is clearly placed on a named key worker who must actively follow up patients. There is no power of recall, but if there is non-compliance, or there is a deterioration in clinical condition, the key worker would have a duty to ensure the patient is reviewed. Re-admission against a patient's will could only occur if the patient fulfilled criteria for 
Table 1. Respondents' views on supervised discharge, extending leave of absence and extending powers of guardlanship. Results are numbers (and percentages) of replies of 42 psychiatrists and 34 approved social workers

\begin{tabular}{|c|c|c|}
\hline & Poychiatists & Social workers \\
\hline & $n(\%)$ & $n(\%)$ \\
\hline $\begin{array}{l}\text { Supervised discharge } \\
\text { Is proposal clear? } \\
\text { Prepared to use? }\end{array}$ & $\begin{array}{l}30(71) \\
39(93)\end{array}$ & $\begin{array}{l}27(79) \\
24(71)\end{array}$ \\
\hline $\begin{array}{l}\text { Reasons reluctant to use supervised discharge? } \\
\text { Unnecessary if current legislation used properly } \\
\text { Will damage doctor or social worker/patient relationship } \\
\text { An infringement of clvil liberties } \\
\text { Unnecessary if CPA used property } \\
\text { May lead to patients avoiding service } \\
\text { Generate increased workload, for which resources unavailable } \\
\text { Used instead of proper resourced community care } \\
\text { No sanction if patient does not comply }\end{array}$ & $\begin{array}{l}13(31) \\
9(21) \\
11(26) \\
17(40) \\
16(38) \\
28(67) \\
24(57) \\
28(67)\end{array}$ & $\begin{array}{l}14(41) \\
9(26) \\
17(50) \\
18(53) \\
20(59) \\
20(59) \\
22(65) \\
21(62)\end{array}$ \\
\hline $\begin{array}{l}\text { Extended leave of absence } \\
\text { Prepared to use? } \\
\text { Would it be useful? }\end{array}$ & $\begin{array}{l}35(83) \\
24(57)\end{array}$ & - \\
\hline $\begin{array}{l}\text { Extension of powers of guardianship } \\
\text { Is proposal clear? } \\
\text { Would it be useful? }\end{array}$ & $\begin{array}{l}24(57) \\
15(36)\end{array}$ & $\begin{array}{l}18(53) \\
15(44)\end{array}$ \\
\hline $\begin{array}{l}\text { Reasons for reluctance to use current guardianship } \\
\text { Patlents do not agree } \\
\text { Difficult to gain access if patient unwilling } \\
\text { No way of enforcing provision if patient unwilling } \\
\text { Relatives do not agree to guardianship } \\
\text { Does not ensure patients recelve care needed } \\
\text { Guardianship legislation unclear } \\
\text { Not part of my usual practice to consider it }\end{array}$ & $\begin{array}{l}17(40) \\
28(67) \\
37(88) \\
12(29) \\
29(69) \\
15(36) \\
8(19)\end{array}$ & $\begin{array}{r}17(50) \\
21(62) \\
28(82) \\
9(26) \\
17(50) \\
9(26) \\
6(18)\end{array}$ \\
\hline
\end{tabular}

compulsory admission under the existing Mental Health Act.

Extended leave of absence. Under current arrangements a patient who is compulsorily detained, may be allowed leave of absence for up to six months under section 17 of the Mental Health Act. During this period patients remain liable to recall at the discretion of the Responsible Medical Officer. As an interim measure it is proposed that the six month time limit be extended to 12 months.

Extending powers of guardianship. The powers of the guardian would be increased. The only new power specified so far, is the power to convey a patient to a place where he or she is required to attend.

This study sought to determine the opinions of a sample of psychiatrists and approved social workers towards the proposed legislation.

\section{The study}

A postal questionnaire was sent in November and December 1993 to a sample of psychiatrists and social workers in the Oxford Health Region. All
52 consultant psychiatrists with responsibility for adult mental illness and a random sample of 52 of 169 approved social workers were sent a questionnaire. One reminder was sent to nonresponders after three weeks. The questions were a combination of forced choice closed questions and open questions inviting written comments. Part of the questionnaire was adapted from a survey by Burns (1993) into attitudes towards community supervision orders. An extract from the Department of Health's publication Legal Powers on the Care of Mentally III People in the Community (Department of Health, 1993) describing the proposals was enclosed.

\section{Findings}

The response rate for psychiatrists was 42 of $\mathbf{5 2}$ $(81 \%)$ and for social workers 34 of $52(65 \%)$.

Supervised discharge. Seventy-one per cent of psychiatrists and $79 \%$ of social workers thought they understood the proposal. However many were unclear about important aspects, in particular whether a requirement to attend for 
medical treatment meant that patients/clients could be required to accept medical treatment. Ninety-four per cent and $71 \%$ respectively were prepared to use this legislation. Respondents were offered eight possible reasons that might make them reluctant to use the new legislation. Psychiatrists and social workers identified the same three main concerns: increased work would be generated with no extra resources available, there would be no sanction on the patient if he or she did not comply and it would be used instead of properly resourced community care.

In written comments, many respondents stated they did not think a supervised discharge order would contain new powers despite being described as a new power. In fact, it seemed to depend upon co-operation from the patient. Two typical comments were: "It does not address the possibility of failure to agree" and "There are no extra powers in difficult situations". Many respondents emphasised their concerns that the order would be difficult to implement without increased resources. Others could not see any advantages over the current guardianship arrangements which are unpopular and little used. A number of respondents had misgivings about the emphasis placed on the key worker who could be at risk from certain patients, for example those with paranoid ideas.

Extended leave of absence (only psychiatrists were asked about this proposal). Eighty-three per cent were prepared to use an extension of leave of absence from six months to one year. Fifty-seven per cent believed it would be useful.

In written comments, respondents expressed concern that extended leave of absence could be coercive and liable to abuse, for example: “. . . it is a deliberate misuse of the Mental Health Act which provides for inpatient treatment, it is a Community Treatment Order without a name". Another psychiatrist commented: "This is an unsatisfactory compromise, it has all the human rights problems without the possible gain of long term prevention". Other respondents believed that it could be helpful for some patients but that it would be completely impractical if it was necessary to keep a bed avallable for the patient on leave, given the current pressure on beds.

Extending guardianship. Forty per cent of psychiatrists and $47 \%$ of social workers found the proposed extension of the existing powers of guardianship unclear. We asked respondents to suggest extended powers of guardianship which would be useful. The most common suggestion among both social workers and psychiatrists, apart from mentioning the need for more resources, was some way of compelling patients to receive treatment, including medication. However, respondents emphasised that stringent safeguards would be needed and felt that compulsory treatment would present practical and moral problems.

Current guardianship legislation is unpopular and seldom used. As the reasons for this are not known we offered seven arguments against the current guardianship arrangements and invited respondents to indicate any that make them reluctant to use guardianship. For both psychiatrists and social workers the same three concerns predominated: there is no way of enforcing provisions if the patient is unwilling; it is difficult to gain access to patients if patients are unwilling; and it did not ensure that patients received the care they needed.

Most respondents reported disappointing experiences with guardianship. A psychiatrist commented: "I am not aware of any case in which it has been successfully employed". A social worker wrote: "Instruction as to where someone is to live is fine but if they refuse there's no power to enforce the provisions of guardianship. It's the horse to water story-how do you make it drink?"

\section{Comment}

Perhaps the most important finding in our survey was that practitioners were unclear about the content of the proposed legislation. Wider consultation with mental health professionals is therefore recommended before the proposals are debated in parliament. Overall there was a striking similarity between the opinions of psychiatrists and social workers. Both saw a need for assertive follow-up and treatment, and many seemed to be supporting moves towards what would essentially be a community treatment order. However, it was acknowledged that there would be major practical and ethical problems in attempting to provide this. Many also had concerns that new legislation would be imposed without the resources needed to implement any new powers. It has been argued that this position would be unethical (Eastman, 1994). Neither group appeared to believe that supervised discharge as currently proposed, or extending guardianship, would be useful additions to mental health legislation.

Supervised discharge can be seen as a way of side-stepping the compulsory treatment $v$. civil liberties debate. It does not contain new powers but is a means of trying to ensure high quality aftercare by placing responsibility firmly upon the team caring for the patient. The key worker in particular carries a heavy obligation. There is apprehension that the key worker might be scapegoated for treatment failures, without having had access to the resources to provide adequate care. Supervised discharge was perceived 
as little different from using the existing care programme approach with assessments under the Mental Health Act for compulsory admission should the patient's health deteriorate.

Most psychiatrists believed extending leave of absence would be useful but there were reservations about the ethical and legal implications. Many felt it was unduly coercive and baulked at the prospect of having patients in the community for periods of up to a year subject to the provisions of what is fundamentally an in-patient treatment order.

There is a risk that the public and interested groups will believe that supervised discharge would offer new powers to enable safe and effective community care. In fact it appears to provide virtually no new powers. It does put increased responsibility on mental health workers to provide assertive follow-up for this vulnerable group and, may lead to improved co-ordination between agencies. This could help identify patients at an earlier stage of relapse. However, if patients refused care and treatment, their mental health would still have to deteriorate to the extent that compulsory admission was warranted before they could receive the care they needed.

The Department of Health has addressed the problem of ensuring effective community care for a small group of difficult to manage patients within the least restrictive legal framework. It has been under pressure to act rapidly following several well-publicised fallures of community care. However we are concerned that new legislation has been put forward which appears to tinker with the problem. It may be more appropriate, for the present, to continue encouraging the best possible use of existing legislation. something the Department of Health itself has advocated.
An alternative approach, argued by Eastman, 1994, would be a radical reform of mental health legislation with removal of the distinction between in-patient and out-patient care. In addition, civil liberties would only be removed from patients if resources to treat them were adequate, a state of affairs that does not always prevail at present.

\section{Acknowledgements}

We thank Professor Robert Bluglass, Dr Derek Chiswick and Professor Michael Gelder for their advice.

\section{References}

BLUGLASS, R. (1993a) Maintaining the treatment of mentally ill people in the community. British Medical Journal, $\mathbf{3 0 6}$. 159-160.

- (1993b) New powers of supervised discharge of mentally ill people. Brttish Medical Journal, 307, 1160.

BurNS, T. (1993) In Health Committee 5th Report: Community Supervision Orders. 667-II Minutes of Evidence and Appendices. London: HMSO

- (1994) Mrs Bottomley's Ten Point Plan. Psychtatric Bulletin, 18, 129-130.

DEPARTMENT OF HEALTH (1993) Legal Powers on the Care of Mentally II People in the Community. Report of the Internal Review. London: Department of Health.

EASTMAN, N. (1994) Mental health law: ctvil liberties and the principle of reciprocity. British Medical Journal. 308. 43-45.

HeAlth Commitree 5TH RePORT (1993) Community Supervision Orders. 667-II Minutes of Evidence and Appendices. London: HMSO

Royal College of Psychiatrists (1993) Community Supervision Orders. London: Royal College of Psychiatrists.

Simon Hampson, Senior Registrar; and Phil Davison, Sentor Registrar, The Warneford Hospital, Oxford OX3 7JX 